\title{
Carotid paragangliomas: case report and imaging review
}

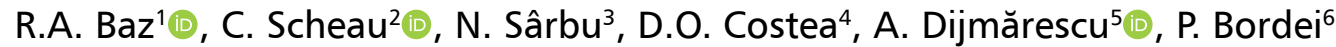 \\ 'Department of Radiology, "Sf. Apostol Andrei" County Hospital, Constanta, Romania \\ 2Department of Physiology, Carol Davila University of Medicine and Pharmacy, Bucharest, Romania \\ ${ }^{3}$ Department of Radiology, Faculty of Medicine and Pharmacy "Dunărea de Jos" Galati, Romania \\ ${ }^{4}$ Department of Surgery, "Sf. Apostol Andrei" County Hospital, Constanta, Romania \\ ${ }^{5}$ Department of Radiology, Fundeni Clinical Institute, Bucharest, Romania \\ ${ }^{6}$ Department of Anatomy, Faculty of Medicine, Constanta, Romania
}

[Received: 4 June 2020; Accepted: 29 June 2020; Early publication date: 21 July 2020]

Background: Presentation of case reviews depicting the imaging characteristics of carotid paragangliomas, associated with a thorough analysis of the anatomical morphological features and the current therapeutic strategies.

Materials and methods: We present the cases of 3 patients diagnosed with carotid paragangliomas in our clinic, illustrating diagnostic imaging elements by computer tomography (CT) and magnetic resonance imaging (MRI), but also the postoperative aspect of the carotid system, with respective anatomical, clinical and surgical considerations.

Results: The imaging aspect of the carotid paragangliomas is characterised by a mass of soft tissue with intense contrast enhancement and with "salt and pepper" MRI appearance on conventional spin-echo sequences. The postoperative evolution of the patients included in the article was favourable, without any perioperative complications or signs of local tumour recurrence.

Conclusions: Carotid paragangliomas are rare, often asymptomatic tumours, but with potential for increased malignancy, which raises the need for good knowledge of the cervical region pathology as well as the features of neuroendocrine tumours. $C T$ and MRI examinations are essential for diagnosis, staging and, implicitly, for establishing the therapeutic strategy. (Folia Morphol 2021; 80, 3: 699-706)

Key words: paraganglioma, carotid body tumour, carotid arteries, diagnostic tools, imaging, therapeutic strategy

\section{INTRODUCTION}

Carotid paragangliomas (CPs), also known as carotid body tumours, are neuroendocrine tumours originating in the parenchymal cells of the neuroectoderm and neural crests, but also in the mesodermal elements of the third branchial arch [1, 17, 19, 28, 30]. Thus, the cells that make up paragangliomas are similar to the cells in the amine precursor uptake and decarboxylation system and can release catecholamines, cholecystokinin, serotonin, somatostatin, and vasoactive intestinal peptide [20].

Paragangliomas have variable localisation and may develop in the head, neck, thorax, or abdomen. Head and neck paragangliomas can show the follow-

Address for correspondence: C. Scheau, MD, PhD, 8 Eroii Sanitari Blvd., 5th district, 050474, Bucharest, Romania, tel: +40213103722 , e-mail: cristian.scheau@umfcd.ro

This article is available in open access under Creative Common Attribution-Non-Commercial-No Derivatives 4.0 International (CC BY-NC-ND 4.0) license, allowing to download articles and share them with others as long as they credit the authors and the publisher, but without permission to change them in any way or use them commercially. 


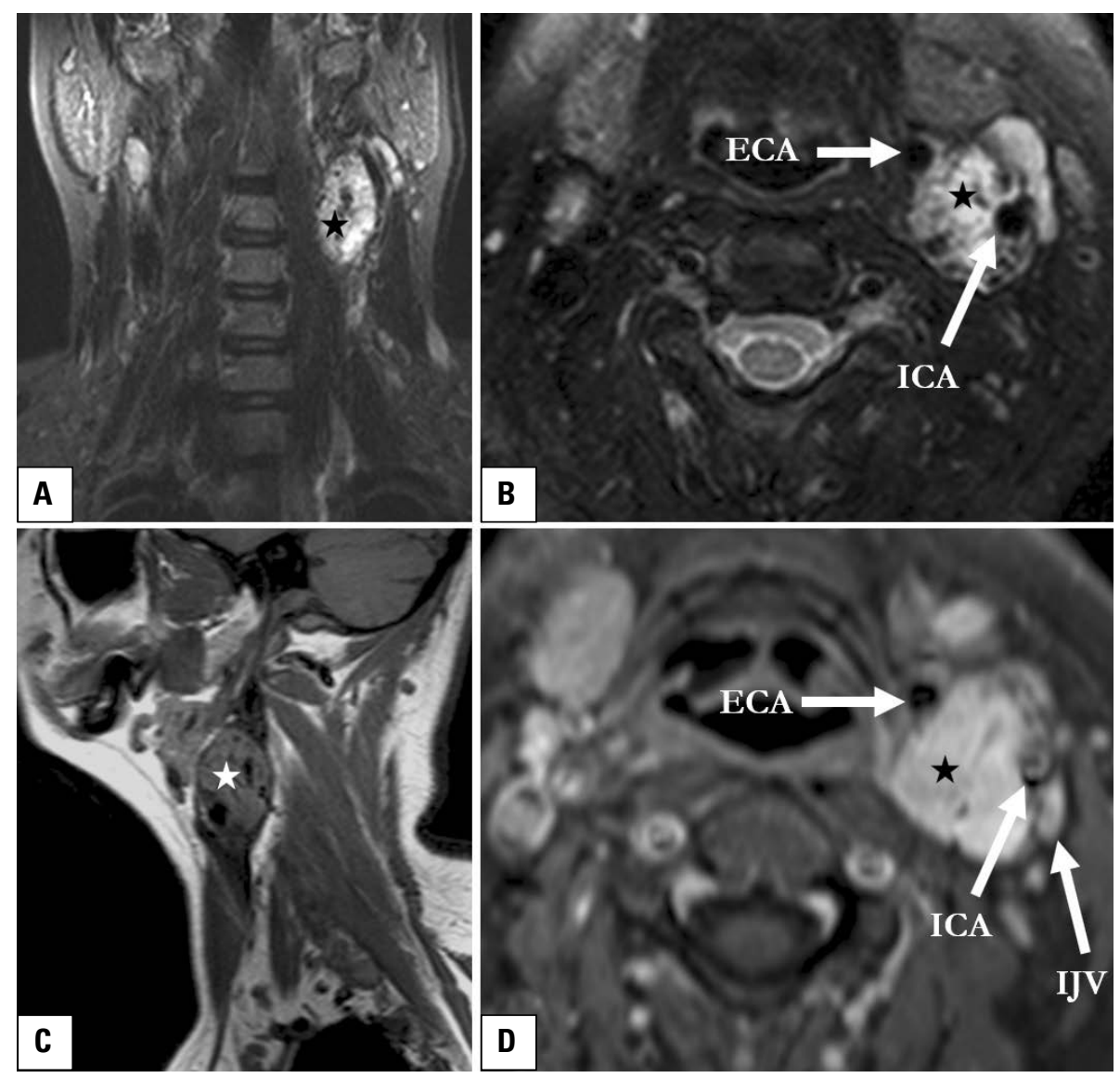

Figure 1. Magnetic resonance imaging investigation consisting of coronal short tau inversion recovery (STIR) (A), axial T2 fat-saturated WI (B), sagittal T1 WI (C), and gadolinium-enhanced axial T1 fat-saturated images depicting a inhomogeneous oval solid mass (star) with intermediate signal on $\mathrm{T} 1 \mathrm{Wl}$ and high signal on $\mathrm{T} 2 \mathrm{Wl}$, intralesional foci in signal void that create an overall "salt and pepper" appearance, developed at the level of left carotid bifurcation (D); the lesion shows intense early enhancement, widens the angle of bifurcation of the common carotid artery and spreads the left external carotid artery (ECA) and internal carotid artery (ICA), without altering their permeability and rapid blood flow signal; IJV - internal jugular vein.

ing topography: carotid (carotid glomus), tympanic (glomus tympani), jugular (glomus jugulare) or vagal (glomus vagale) [22]. These tumours are rare [1, 26, $30]$, can be single or multifocal tumours, and are considered benign but with malignant potential in 6-12\% of cases $[14,19,28,34]$. CPs represent $0.6 \%$ of head and neck neoplasms, accounting for $60-70 \%$ of paragangliomas of the head and neck region, and make up $0.5 \%$ of tumours affecting the entire body $[1,14,34]$.

The majority of paragangliomas are sporadic; however, in about $40 \%$ of cases, family history is demonstrated [5]. Hereditary tumours are more often multicentric and tend to occur earlier than sporadic forms, with a peak incidence at 30-35 years of age [18]. Familial paragangliomas exhibit autosomal dominant transmission and are commonly seen in patients with von Hippel-Lindau disease, type I neurofibromatosis, and type II multiple endocrine neoplasias [23].

The scope of this paper is to mark the essential diagnostic elements of CPs useful to the clinicians and surgeons in planning the therapeutic strategy. Starting from the presentation of 3 illustrative cases investigated in our clinic, we analysed the specific literature data and detailed the most important elements involved in the management of these tumour types.

\section{CASE REPORTS}

\section{Case 1}

A 42-year-old woman was admitted to the hospital for a painless left cervical tumour measuring close to $3 \mathrm{~cm}$, with a soft consistency, and mobile in the transverse plane. The ultrasound showed a submandibular hypoechogenic mass that displaced the internal carotid artery. The magnetic resonance imaging (MRI) examination revealed a hypervascular lesion with a "salt and pepper" appearance located in the left carotid space, at the terminal bifurcation of the common carotid artery, with suggestive characteristics for CP (Fig. 1). The patient refused surgery, but 90 days later she returned determined to receive 

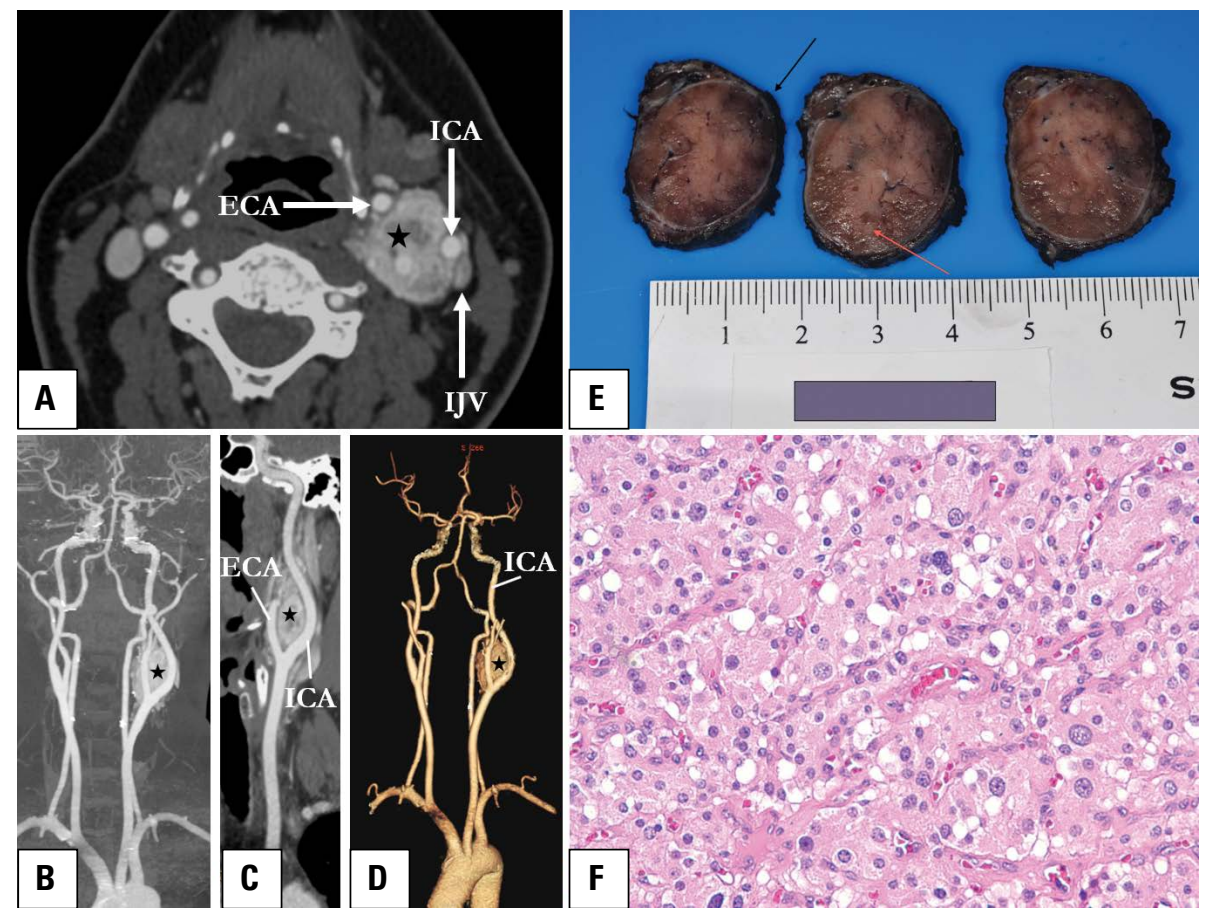

Figure 2. Computed tomography (CT) examination: axial CT angiography (A), coronal-oblique maximum-intensity-projection reformatted image (B), curved-planar reformatted image of the left internal carotid artery (ICA) (C), and three-dimensional volume-rendered reformatted image (D). Large solid mass (star), with intense and slightly inhomogeneous enhancement, located at the level of the left carotid bifurcation, separating the external carotid artery (ECA) and ICA. The described lesion encases about $50 \%$ of the circumference of the ICA, without modifying its lumen (type II Shamblin) and is adjacent to the internal jugular vein (IJV). Macroscopic appearance (E) of the carotid body tumour after complete excision with a pseudo capsule (black arrow) and multiple feeding vessels (orange arrow). Microscopic specimen (F): uniform polygonal cells with abundant eosinophilic granular cytoplasm and large, regular, central nuclei.

treatment. Computed tomography (CT) angiography confirmed a bright and rapidly enhancing mass located at the level of the left carotid bifurcation compatible with a diagnosis of a type II Shamblin CP (Fig. 2). The chosen treatment course implied the surgical cure of the tumour with a favourable postoperative evolution, without incidents, and with no detectable tumour recurrence on imaging follow-up at 3 months and, subsequently, at 6 and 12 months.

\section{Case 2}

A 55-year-old woman with no particular pathological background was admitted with a right cervical mass showing slow dimensional progression within a year, with no other associated symptoms. The clinical examination and ultrasound confirmed the presence of a tumour with soft consistency adjacent to the right internal carotid artery. The MRI and CT examinations revealed a type IIla Shamblin CP, with a characteristic "salt and pepper" appearance at the level of the right carotid bifurcation, with a small extension to the submandibular space and the right postero-lateral wall of the pharynx (Fig. 3). The pa- tient showed favourable postoperative outcome with a good evolution and is periodically evaluated in our clinic, without complications or tumour recurrence at 3.5 years after surgery.

\section{Case 3}

A diabetic 46-year-old woman presented with a left-cervical mass manifested in the last 2 years, with a gradual increase in size and associating dysphonia at the time of hospitalisation. The ultrasound examination suspected a CP by highlighting a hypoechogenic mass at the carotid bifurcation, which splayed the external and internal carotid arteries, extending medially to the retropharyngeal space, anteriorly to the submandibular branch, and posteriorly through the soft prevertebral tissues. CT angiography established the diagnosis of a type IIllb Shamblin CP (Fig. 4). No incidents occurred during the surgical procedure and intraoperative observations confirmed the inclusion and infiltration of the internal carotid artery. The follow-up examinations performed at 3 and 12 months did not reveal any complications or local tumour recurrence. 

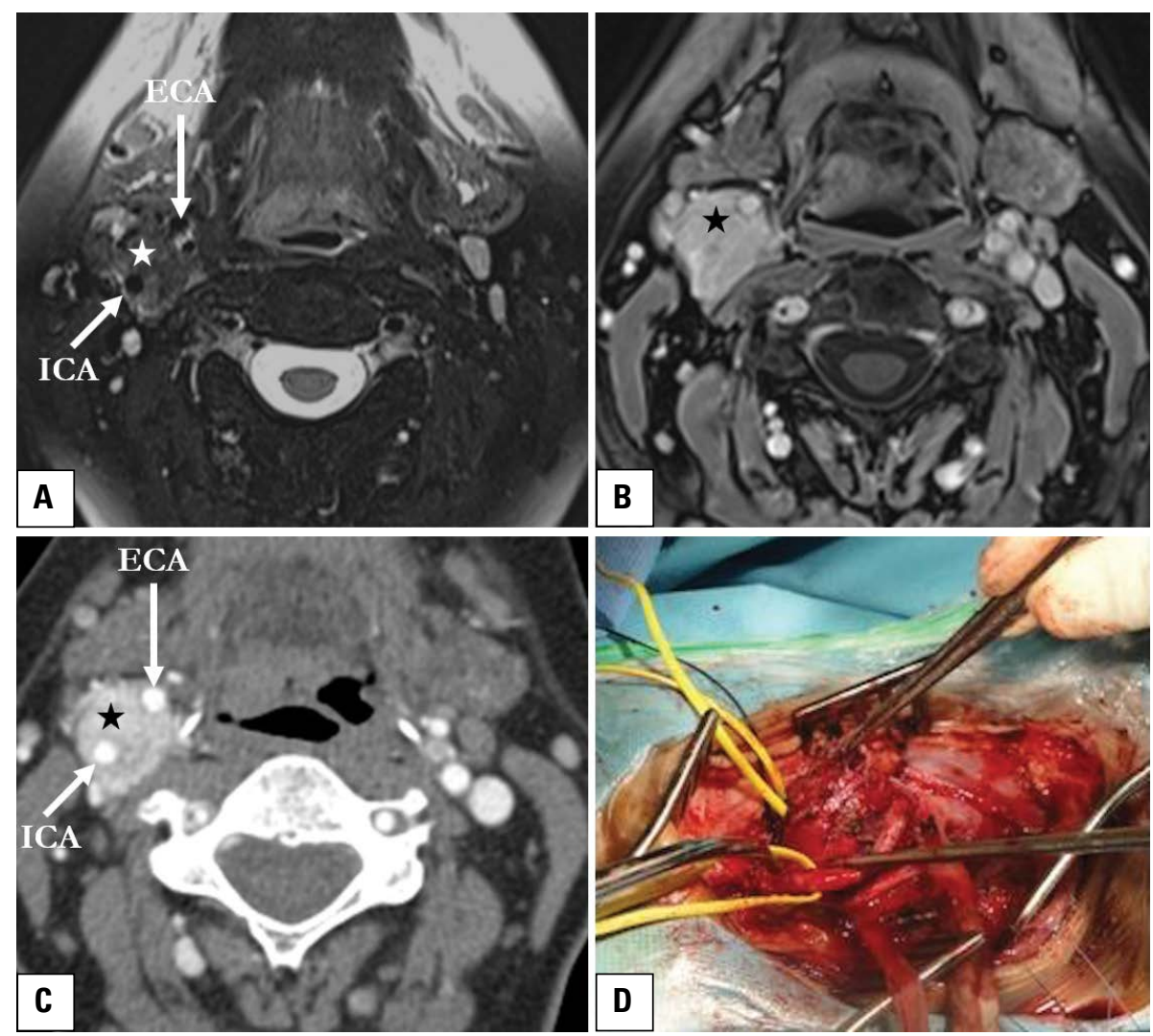

Figure 3. Magnetic resonance imaging saturated $\mathrm{T} 2$ axial fat image $(\mathbf{A})$ and gadolinium-enhanced $\mathrm{T} 1$ fat axial image (B), and axial computed tomography postcontrast-arterial phase (C) showing a solid mass (star) with well-defined contour, inhomogeneous signal, "salt and pepper" aspect, and intense early contrast enhancement, located at the level of the right carotid bifurcation, separating the right internal carotid artery (ICA) and external carotid artery (ECA). The lesion splays the carotid arteries, encloses the ICA and ECA without infiltrating them. Intraoperative view of the carotid body tumour before complete excision (D).

\section{Imaging review of paragangliomas}

Imaging is an essential part of the diagnostic protocol in the management of carotid glomus tumours. CT and MRI examinations using contrast mediums are useful in lesion detection, thus obtaining valuable information regarding the lesion size, the relationship with the adjacent anatomical structures, and the degree of vascularisation. Additionally, blood flow downstream of the lesion can be ascertained, and the presence of collateral circulation, anatomic variants, and other synchronous paragangliomas in other regions of the body can also be demonstrated [33].

Ultrasonography is a first-line imaging method for determining the location and features of lateral-cervical masses. CP appears as a well-delimited round-oval hypoechogenic mass located at the level of the carotid sinus, causing the carotid bifurcation to flare. Colour Doppler or Doppler duplex highlights the hypervascular character of the lesion and allows differentiation from other tumours, but with limited possibilities in detecting local invasion [15].
Computed tomography shows $\mathrm{CP}$ as a soft tissue mass located in the carotid space, with intense and homogeneous early enhancement due to its highly vascular nature. Large tumours may exhibit a heterogeneous structure due to the presence of thrombi or focal haemorrhages. Flaring (splaying) of the external and internal carotid arteries, a hallmark of $\mathrm{CP}$, can also be easily visualised on $\mathrm{CT}$ (Fig. 5). Irradiation and the allergic risk to the iodinated contrast substance are the main disadvantages of $C T$ [32].

Magnetic resonance imaging has proven its superiority to other imaging techniques in offering a more accurate appreciation of lesion margins and invasion of adjacent structures [24]. Using native and contrast-enhanced spin-echo sequences with fat suppression, MRI examination can determine vascular invasion more accurately compared to $\mathrm{CT}$, and can also provide more detailed vascular morphometry measurements [9]; additionally, MRI can reveal lesions smaller than $5 \mathrm{~mm}$, while CT usually depicts lesions larger than $8 \mathrm{~mm}$ [31]. The typical MRI aspect of $C P$ is given by the presence of multiple punctiform or serpentine shaped intralesional 

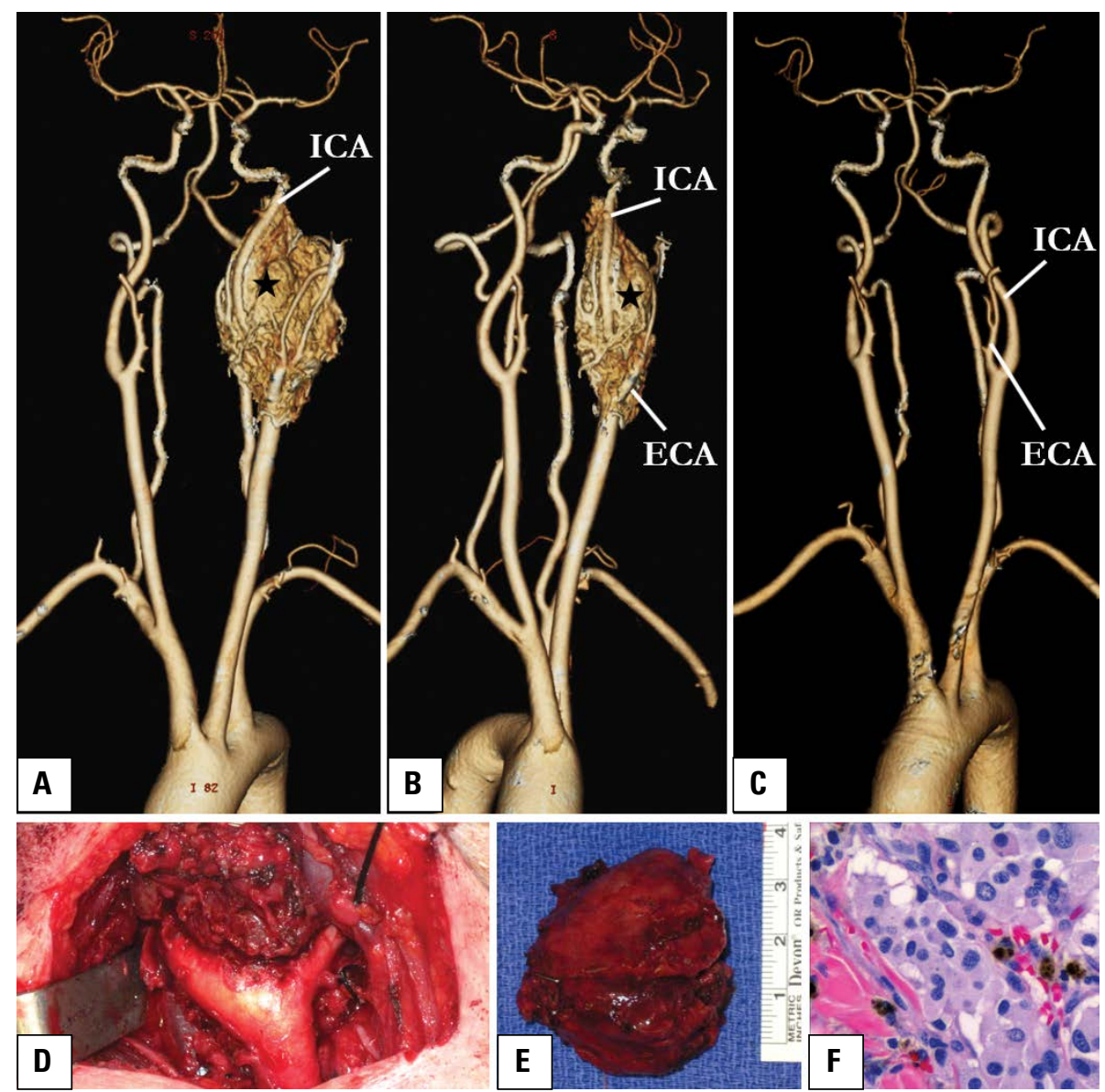

Figure 4. Computed tomography angiography coronal-oblique volume-rendered images pre- (A, B) and postoperatively (C) highlighting a large hypervascular mass (star) at the level of the left carotid bifurcation that splays the carotid arteries and infiltrates the internal carotid wall, correspondingly to a type Illb Shamblin tumour. Imaging performed 1 year after surgery demonstrates the absence of recurrence and normal appearance of the left carotid arteries. Intraoperative appearance of the carotid body tumour (D). Gross pathology specimen with a meaty appearance with a bulging surface (E). Photomicrograph of the histologic specimen (haematoxylin and eosin, $\times 400$ ) showing highly vascularised fibrous septa surrounding the chief neoplastic cells (F); ICA — internal carotid artery; ECA — external carotid artery.
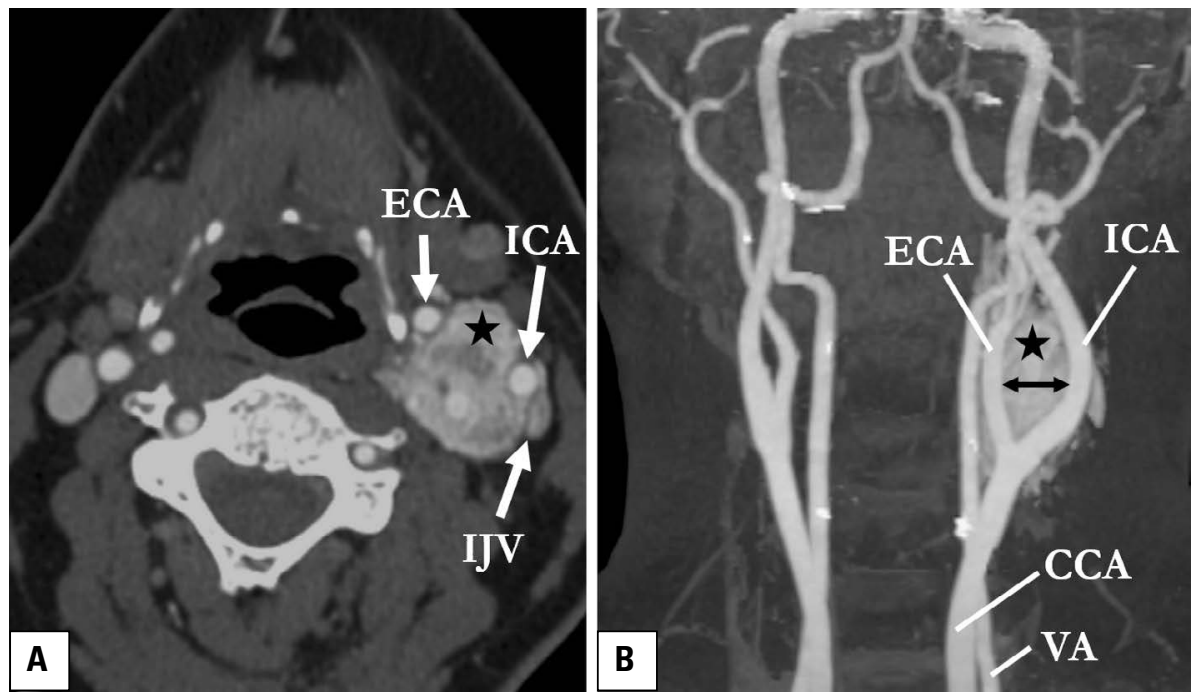

Figure 5. Contrast-enhanced computed tomography: axial images (A) and coronal-oblique maximum-intensity-projection (B) showing a widening of the distance between the left carotid arteries (black arrow) as a result of the development of a carotid body tumour (star). Left side vessels are marked: vertebral (VA), common carotid (CCA), internal carotid (ICA) and external carotid (ECA) arteries. 


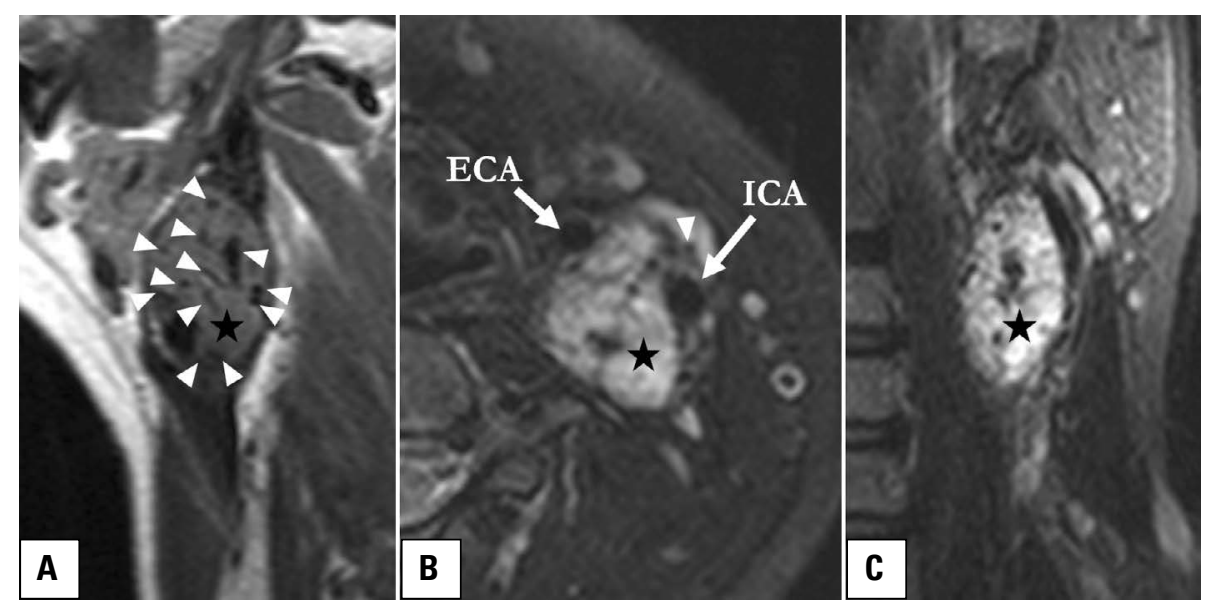

Figure 6. Magnetic resonance imaging aspect of a carotid body tumour with "salt and pepper" sign generated by signal void areas due to numerous intratumoural vessels (arrowheads); A. T1 Wl; B. T2 FS Wl; C. Short tau inversion recovery (STIR) images; ICA — internal carotid artery; ECA - external carotid artery.

foci with signal void. These are caused by the higher flow velocity in the intratumoural vessels and give the whole lesion a "salt and pepper" appearance (Fig. 6). The "salt" represents areas of hyperintensities due to slow vascular flow or microhaemorrhages, while the "pepper" corresponds to the above-mentioned areas with markedly decreased $\mathrm{T} 1$ and $\mathrm{T} 2$ signals (signal void) [15]. This imaging pattern is rarely found in lesions smaller than $1 \mathrm{~cm}$, and can also be observed in other hypervascular tumours such as renal cell carcinoma metastases and thyroid carcinoma metastases [12].

Conventional digital subtraction angiography is the gold standard for evaluating the vascular architecture of these tumours. The typical angiographic aspect of paragangliomas is that of a hypervascular mass which splays the internal and external carotid arteries and presents large feeding arteries, intense arterial flash, and quick contrast washout. The tributary arteries of CPs are the ascending pharyngeal artery and the ascending cervical artery. As the tumour increases in size, contributions from other arterial sources such as the facial, lingual, or thyroid arteries may add up. It is mandatory to note the patency of the internal jugular vein, which may be thrombosed in large CPs [6].

Differential imaging diagnosis of paragangliomas should include nerve sheath tumours that displace the carotid arteries medially and anteriorly while the internal jugular vein is pushed posteriorly, as compared to CPs that splay the carotids; other diagnoses include vagal glomus tumours which display similar morphological characteristics but are more rostrally located, and also hypervascular metastatic adenopathies from renal or thyroid malignancies, which are difficult to distinguish from CPs $[6,32]$. Histopathology is not necessary for the diagnosis and performing a biopsy may even be very dangerous due to the high degree of tumour vascularisation $[21,29]$.

\section{DISCUSSION}

Carotid paragangliomas generally affect women $[1,19,28,30,34]$, are bilateral in about $10 \%$ of cases [6], and the involvement of hereditary factors is described in $4-9 \%$ of cases [28, 30, 34].

From a clinical standpoint, CPs are slow-evolving tumours which may remain painless and generally asymptomatic and for a long period of time, and are located anteriorly to the lateral sternocleidomastoid muscle, showing mobility in the lateral plane, but fixed in the cephalocaudal plane (Fontaine's sign) [31]. CPs significantly alter the loco-regional anatomy, both through their dimensions and their position. Therefore, any lesion that develops adjacent to the terminal bifurcation of the common carotid artery will induce changes in the muscular, vascular, and nervous anatomical relations. Taking into account the vascular nature of the lesion in question, the most apparent altered index could be the angle between the origins of the internal and external carotid arteries. As carotid body tumours grow in size they can invade the parapharyngeal space causing a bulging of the lateral oropharyngeal wall inducing dysphagia, odynophagia, or syndromes associated with cranial nerves IX-XII disorders [35].

Carotid body tumours are paragangliomas that show high malignant capacity, a feature that occurs in $6-12 \%$ of cases $[14,19,28,34]$. In the absence of specific histopathological criteria, malignancy is marked by the anatomical presence of metastases [10], with a predilection for regional lymph nodes, 
and very rare distant metastases [3]. The therapeutic method of choice for carotid body tumours is surgical removal, which in select cases may be preceded by angiographic embolisation $[8,25]$. Embolisation may reduce the size of the tumour and promote its disconnection from the vascular system, thereby reducing intraoperative bleeding $[13,36]$. Among the significant complications of surgical treatment are secondary bleeding, cranial nerve deficiency, and perioperative stroke; therefore, the intervention requires caution in aged patients, especially in patients with cardio-ischaemic pathology despite the general addressability of the surgery $[7,8,13,25,36]$.

The key element in choosing the right therapeutic conduit is the assessment of the extent of tumoural vascular involvement through medical imaging, a method that also provides insight regarding the prognosis and possible complications. As such, a classification system for CP was proposed by Shamblin et al. [27] in 1971 and is currently in use despite its shortcomings regarding the degree of tumour infiltration into the carotid wall, a critical element to be factored when the preservation of the arteries is considered. According to Shamblin et al. [27], type I tumours are located at the bifurcation of the common carotid artery, with minimal contact area with blood vessels, type II encompasses tumours that have a diameter generally less than $5 \mathrm{~cm}$, and include about $50 \%$ of the circumference of the main arterial axis, entailing difficulties for the surgical cure, while type III is reserved for generally large tumours with a diameter greater than $5 \mathrm{~cm}$, that completely enclose the main arterial axis [27].

Luna-Ortiz et al. [16] emphasizes that imaging by axial sections does not accurately approximate the carotid wall tumour infiltration preoperatively, but it highlights the circumferential ratio of the tumour to the adjacent vascular structures. Thus, in 2006, Luna-Ortiz et al. [16] proposed the introduction of a grade Illb to the carotid paragangliomas, which, regardless of their size, infiltrate the carotid wall. According to Luna-Ortiz et al. [16], type Illa is superimposed on the old (Shamblin) type III, respectively CPs that include the vessels without infiltrating them.

A study by Arya et al. [2] sustains a good correlation between the radiological aspects of the Shamblin classification and surgical results, and concludes that without taking into account the tumour size, the maximum degree of circumferential tumour/artery contact should be the only criterion for the Shamblin classification, therefore predicting the degree of vascular viability [2].
Radiation therapy, alone or associated with surgery, is another therapeutic strategy that can be chosen in the case of carotid glomus tumours. The treatment is based on the induction of local fibrosis, which can stop tumour development and is indicated in inoperable cases or postoperative relapses $[4,11]$.

\section{CONCLUSIONS}

Carotid paragangliomas are hypervascular tumours, with imaging features of a soft tissue mass with intense enhancement and "salt and pepper" appearance on MRI in conventional spin-echo sequences.

The radiological examination is essential for diagnosis and establishing of the therapeutic strategy. Firstly, the tumour must be detected and characterised, and secondly, the lesion extension must be appreciated in regard to the surrounding vascular structures. Last but not least, the presence of concomitant tumours should be verified, considering that paragangliomas are multifocal lesions in $30 \%$ of patients.

Considering all the information presented, the medical team managing a CP case should benefit from a mindful preoperative planning and a correct selection of patients, in order to obtain a successful therapeutic result.

\section{Compliance with ethical standards and informed consent}

The study was performed in compliance with the local institutional research ethics committee and was carried out in accordance with the ethical standards of the Declaration of Helsinki and its later amendments. Informed consent was obtained from all participants included in the study.

Conflict of interest: None declared

\section{REFERENCES}

1. Albsoul NM, Alsmady MM, Al-Aardah MI, et al. Carotid body paraganglioma management and outcome. Eur J Sci Res. 2009; 37(4): 567-574.

2. Arya S, Rao V, Juvekar S, et al. Carotid body tumors: objective criteria to predict the Shamblin group on MR imaging. Am J Neuroradiol. 2008; 29(7): 1349-1354, doi: 10.3174/ ajnr.A1092, indexed in Pubmed: 18417602.

3. Boedeker CC, Neumann HPH, Maier W, et al. Malignant head and neck paragangliomas in SDHB mutation carriers. Otolaryngol Head Neck Surg. 2007; 137(1): 126-129, doi: 10.1016/j. otohns.2007.01.015, indexed in Pubmed: 17599579.

4. Carroll W, Stenson K, Stringer S. Malignant carotid body tumor. Head Neck. 2004; 26(3): 301-306, doi: 10.1002/ hed.20017, indexed in Pubmed: 14999807.

5. Dahia PLM. Pheochromocytoma and paraganglioma pathogenesis: learning from genetic heterogeneity. Nat 
Rev Cancer. 2014; 14(2): 108-119, doi: 10.1038/nrc3648, indexed in Pubmed: 24442145.

6. Davidovic LB, Djukic VB, Vasic DM, et al. Diagnosis and treatment of carotid body paraganglioma: 21 years of experience at a clinical center of Serbia. World J Surg Oncol. 2005; 3(1): 10, doi: 10.1186/1477-7819-3-10, indexed in Pubmed: 15707500.

7. Davila VJ, Chang JM, Stone WM, et al. Current surgical management of carotid body tumors. J Vasc Surg. 2016; 64(6): 1703-1710, doi: 10.1016/j.jvs.2016.05.076, indexed in Pubmed: 27871494.

8. Dixon JL, Atkins MD, Bohannon WT, et al. Surgical management of carotid body tumors: a 15-year single institution experience employing an interdisciplinary approach. Proc (Bayl Univ Med Cent). 2016; 29(1): 16-20, doi: 10.1080/08998280.2016.11929343, indexed in Pubmed: 26722157.

9. Farımaz M, Çelik HH, Ergun KM, et al. The morphometry of the cavernous part of the internal carotid artery. Folia Morphol. 2019; 78(1): 54-62, doi: 10.5603/FM.a2018.0045, indexed in Pubmed: 29802716.

10. Fliedner SMJ, Lehnert $H$, Pacak K. Metastatic paraganglioma. Semin Oncol. 2010; 37(6): 627-637, doi: 10.1053/j.seminoncol.2010.10.017, indexed in Pubmed: 21167381.

11. Gilbo P, Morris CG, Amdur RJ, et al. Radiotherapy for benign head and neck paragangliomas: a 45-year experience. Cancer. 2014; 120(23): 3738-3743, doi: 10.1002/cncr.28923, indexed in Pubmed: 25060724.

12. Itawi SA, Buehler M, Mrak RE, et al. A unique case of carotid splaying by a cervical vagal neurofibroma and the role of neuroradiology in surgical management. Cureus. 2017; 9(9): e1658, doi: 10.7759/cureus.1658, indexed in Pubmed: 29147633.

13. Jackson RS, Myhill JA, Padhya TA, et al. The effects of preoperative embolization on carotid body paraganglioma surgery: a systematic review and meta-analysis. Otolaryngol Head Neck Surg. 2015; 153(6): 943-950, doi: 10.1177/0194599815605323, indexed in Pubmed: 26378186.

14. Lee JH, Barich F, Karnell LH, et al. National Cancer Data Base report on malignant paragangliomas of the head and neck. Cancer. 2002; 94(3): 730-737, doi: 10.1002/cncr.10252, indexed in Pubmed: 11857306.

15. Lee KiY, Oh YW, Noh HJ, et al. Extraadrenal paragangliomas of the body: imaging features. Am J Roentgenol. 2006; 187(2): 492-504, doi: 10.2214/AJR.05.0370, indexed in Pubmed: 16861555.

16. Luna-Ortiz K, Rascon-Ortiz M, Villavicencio-Valencia V, et al. Does Shamblin's classification predict postoperative morbidity in carotid body tumors? A proposal to modify Shamblin's classification. Eur Arch Otorhinolaryngol. 2006; 263(2): 171-175, doi: 10.1007/s00405-005-0968-4, indexed in Pubmed: 16010570.

17. Malec K, Cenda P, Brzewski P, et al. Paragangliomas of head and neck: A surgical challenge. J Craniomaxillofac Surg. 2017; 45(1): 127-130, doi: 10.1016/j.jcms.2016.10.003, indexed in Pubmed: 27842922.

18. Mannelli M, Castellano M, Schiavi F, et al. Clinically guided genetic screening in a large cohort of italian patients with pheochromocytomas and/or functional or nonfunctional paragangliomas. J Clin Endocrinol Metab. 2009; 94(5): 1541-1547, doi: 10.1210/jc.2008-2419, indexed in Pubmed: 19223516.

19. McCrary HC, Babajanian E, Calquin M, et al. Characterization of malignant head and neck paragangliomas at a single institution across multiple decades. JAMA Otolaryngol Head
Neck Surg. 2019; 145(7): 641-646, doi: 10.1001/jamaoto.2019.1110, indexed in Pubmed: 31194233.

20. Moore MG, Netterville JL, Mendenhall WM, et al. Head and neck paragangliomas: an update on evaluation and management. Otolaryngol Head Neck Surg. 2016; 154(4): 597-605, doi: 10.1177/0194599815627667, indexed in Pubmed: 26861230.

21. Muhm M, Polterauer P, Gstöttner W, et al. Diagnostic and therapeutic approaches to carotid body tumors. Review of 24 patients. Arch Surg. 1997; 132(3): 279-284, doi: 10.1001/archsurg.1997.01430270065013, indexed in Pubmed: 9125028.

22. Obholzer RJ, Hornigold R, Connor S, et al. Classification and management of cervical paragangliomas. Ann R Coll Surg Engl. 2011; 93(8): 596-602, doi: 10.1308/147870811X131 37608455172, indexed in Pubmed: 22041235.

23. Offergeld C, Brase C, Yaremchuk S, et al. Head and neck paragangliomas: clinical and molecular genetic classification. Clinics. 2012; 67(S1): 19-28, doi: 10.6061/clinics/2012(sup01)05.

24. Olsen WL, Dillon WP, Kelly WM, et al. MR imaging of paragangliomas. Am J Roentgenol. 1987; 148(1): 201-204, doi: 10.2214/ajr.148.1.201, indexed in Pubmed: 3024473.

25. Pacheco-Ojeda LA. Carotid body tumors: Surgical experience in 215 cases. J Craniomaxillofac Surg. 2017; 45(9): 1472-1477, doi: 10.1016/j.jcms.2017.06.007, indexed in Pubmed: 28687470.

26. Rush BF. Jr. Current concepts in the treatment of carotid body tumors. Surgery. 1962; 52: 679-684, indexed in Pubmed: 14495345.

27. Shamblin WR, ReMine WH, Sheps SG, et al. Carotid body tumor (chemodectoma). Am J Surg. 1971; 122(6): 732-739, doi: 10.1016/0002-9610(71)90436-3.

28. Sobol SM, Dailey JC. Familial multiple cervical paragangliomas: report of a kindred and review of the literature. Otolaryngol Head Neck Surg. 1990; 102(4): 382-390, doi: 10.1177/019459989010200413, indexed in Pubmed: 2113266.

29. Somasundar $P$, Krouse $R$, Hostetter $R$, et al. Paragangliomas? A decade of clinical experience. J Surg Oncol. 2000; 74(4): 286-290, doi: 10.1002/1096-9098(200008)74:4<286::aidjso9>3.0.co;2-c.

30. Sykes J, Ossoff R. Paragangliomas of the Head and Neck. Otolaryngol Clin North Am. 1986; 19(4): 755-767, doi: 10.1016/s0030-6665(20)31720-5.

31. Thelen J, Bhatt AA. Multimodality imaging of paragangliomas of the head and neck. Insights Imaging. 2019; 10(1): 29, doi: 10.1186/s13244-019-0701-2, indexed in Pubmed: 30830483.

32. van den Berg R. Imaging and management of head and neck paragangliomas. Eur Radiol. 2005; 15(7): 1310-1318, doi: 10.1007/s00330-005-2743-8, indexed in Pubmed: 15809825.

33. West $C T$, Brassett $C$, Gaunt ME. Variations in carotid sinus anatomy and their relevance to carotid interventions. Folia Morphol. 2018; 77(4): 693-697, doi: 10.5603/ FM.a2018.0017, indexed in Pubmed: 29500893.

34. Williams MD. Paragangliomas of the head and neck: an overview from diagnosis to genetics. Head Neck Pathol. 2017; 11(3): 278-287, doi: 10.1007/s12105-017-0803-4, indexed in Pubmed: 28321772.

35. Woolen S, Gemmete JJ. Paragangliomas of the Head and Neck. Neuroimaging Clin N Am. 2016; 26(2): 259-278, doi: 10.1016/j.nic.2015.12.005, indexed in Pubmed: 27154608.

36. Zeitler DM, Glick J, Har-El G. Preoperative embolization in carotid body tumor surgery: is it required? Ann Otol Rhinol Laryngol. 2010; 119(5): 279-283, doi: 10.1177/000348941011900501, indexed in Pubmed: 20524570. 